IP Periodica Polytechnica

Social and Management

Sciences

25(1), pp. 56-63, 2017

DOI: $10.3311 /$ PPso.9326

Creative Commons Attribution (i)

RESEARCH ARTICLE

\section{Development of the Work-Related Well-Being Questionnaire Based on Seligman's PERMA Model}

\author{
Ágota Kun ${ }^{1 *}$, Péter Balogh², Katalin Gerákné Krasz ${ }^{1}$
}

Received 12 April 2016; accepted 27 June 2016

\begin{abstract}
Drawing on recent research on determinants of subjective well-being, we developed and conducted a pilot study of an employee well-being questionnaire using M. Seligman's (2011) multidimensional PERMA model (Positive emotion, Engagement, positive Relationships, Meaning, and Accomplishment) model. Employees $(N=397)$ from postgraduate courses at the Budapest University of Technology and Economics (BME) completed a survey including 56 items which were theoretically relevant to the PERMA theory. Factor analyses recovered the expected five PERMA components and a negative emotion factor. Based on factor and reliability analyses, we reduced the 56 PERMA items to 35 items. Our results support the multidimensional approach to defining and measuring multidimensional well-being. A multidimensional well-being assessment may be useful for understanding employees' well-being, which can then be applied when developing policy and practice to increase well-being for all employees at work.
\end{abstract}

\section{Keywords}

positive psychology, well-being, PERMA model, PERMA at work, measurement

\footnotetext{
${ }^{1}$ Department of Ergonomics and Psychology, Faculty of Economics and Social Sciences, Budapest University of Technology and Economics, Hungary

2 iCons-Hungary Humánfejlesztő és Tanácsadó Kft.

6723 Szeged, 13 Sándor u., Hungary

*Corresponding author, e-mail: agotak@erg.bme.hu
}

\section{Introduction}

\subsection{Positive psychology}

Positive psychology is a quite new branch of psychology the roots of which can be traced back to Martin E. P. Seligman's 1998 Presidential Address to the American Psychological Association (Seligman, 1998). As APA president, Seligman initiated a shift in psychology's focus toward more positive psychological topics, such as well-being, contentment, hope, optimism, flow, happiness, savouring, human strengths, and resilience. In contrast with the classical focus of psychology on curing mental illness, positive psychology emphasizes understanding the factors that build strengths, help people to flourish and contribute to mental health, as well as on subjective wellbeing and happiness. All of these factors and processes may underlie optimal human functioning.

The message of the positive psychology movement is to remind our field that it has been deformed. Psychology is not just the study of disease, weakness, and damage; it also is the study of strength and virtue. Treatment is not just fixing what is wrong; it also is building what is right. Psychology is not just about illness or health; it also is about work, education, insight, love, growth, and play. And in this quest for what is best, positive psychology does not rely on wishful thinking, selfdeception, or hand waving; instead, it tries to adapt what is best in the scientific method to the unique problems that human behavior presents in all its complexity (Seligman, 2002, p. 4).

Considering the basic statement Seligman proposed, how can we define positive psychology? There are as many definitions as there are positive psychologists, for example: "Positive psychology is a scientific field that studies the optimal functioning of individuals, groups, and institutions" (Gable and Haidt, 2005). "Positive psychology is about scientifically informed perspectives on what makes life worth living. It focuses on aspects of the human condition that lead to happiness, fulfilment, and flourishing" (The Journal of Positive Psychology, 2005). "It is nothing more than the scientific study of ordinary human strengths and virtues. Positive psychology revisits 'the average person,' with an interest in finding out what works, what is right, and what is improving ... positive psychology is simply psychology" 
(Sheldon and King, 2001, p. 216). "Positive Psychology is an umbrella term for theories and research about what makes life most worth living" (Seligman and Csikszentmihalyi, 2000).

Positive psychology does not, however, imply that other applied fields of psychology (e.g. clinical, social or health psychology) are negative, although the science of psychology has made great efforts to understand what goes wrong in individuals, groups, and institutions while paying much less attention to understanding what is 'right' with people. Psychologists need to recognize the importance and practical utility of focusing on positive emotions, positive relationships, positive traits, and positive human functioning.

According to Seligman (2002), positive psychology has three primary concerns. The first is to specify and measure positive traits 'that transcend particular cultures and politics and approach universality' (Seligman, 1998, p. 1). Understanding positive individual traits involves the study of strengths, such as the capacity for love and work, courage, compassion, resilience, creativity, curiosity, integrity, self-knowledge, moderation, self-control, and wisdom. The second goal is to promote positive experiences and emotions. Understanding positive emotions entails the study of contentment with the past, happiness in the present, and hope for the future. The third focus is on understanding positive institutions that entails the study of the strengths that foster better communities, such as justice, responsibility, civility, parenting, nurturance, the work ethic, leadership, teamwork, purpose, and tolerance (Positive Psychology Center). As a science it employs and develops assessments and research designs to establish trustworthy findings which can be related to practical application.

\subsection{Concept of well-being}

Well-being has been a longstanding topic of research interest. The central objective of positive psychology is to facilitate happiness and subjective well-being (Seligman, 2002). Positive psychologists attempt to measure well-being from a positive-based standpoint (e.g. increasing subjective well-being, promoting mental health and personal thriving). The positive psychology movement characterizes well-being as "positive and sustainable characteristics which enable individuals and organizations to thrive and flourish" (Well-being Institute, University of Cambridge). Many theorists have suggested that well-being has multiple domains, and is thus a multifaceted construct (Forgeard et al., 2011; Stiglitz et al., 2009; Diener, 2009; Michaelson et al., 2009). Ryff and Keyes (1995) suggest six domains and Huppert and So (2013) identify 10 items associated with flourishing. Well-being is a dynamic concept that includes not only subjective, social and psychological dimensions, but also health-related behaviours and economic aspects (e.g. financial success).

Diener and Seligman (2004) pointed out that a more systematic approach is needed, as the "current measurement of well-being is haphazard, with different studies assessing different concepts in different ways" (p. 2). The multiplicity of approaches to the study of well-being has resulted in somewhat broad definitions of well-being, with researchers using the construct of 'well-being' synonymously with 'satisfaction', 'happiness', or 'quality of life'.

\subsubsection{Seligman's PERMA model}

Seligman (2011) suggests five components of well-being, and developed a new model of well-being which he called PERMA (PERMA is an acronym formed from the first letters of each domain defined by Seligman as a determinant of wellbeing). Seligman's new theory posits that well-being consists of the nurturing of one or more of the five following elements: Positive emotion, Engagement, Relationships, Meaning and Accomplishment. The five domains essential to well-being are:

Positive emotions Good feelings motivate many human actions. Individuals read, travel or do whatever makes them feel happy and joyful. Positive emotions enhance performance at work, boost physical health, they strengthen relationships, and create optimism and hope for the future.

Engagement This refers to attachment, involvement, concentration, and the level of inclination towards activities such as recreation, hobbies, or work (Higgins, 2006; Schaufeli et al., 2006). A key concept is flow, when time seems to stand still and one loses one's sense of self, and concentrates intensely on the present. In positive psychology, ,flow' describes a state of utter, blissful immersion in the present moment. When we focus on doing the things we truly enjoy and care about, we can begin to engage completely with the present moment and enter the state of being known as ,flow' (Seligman, 2011).

Relationships We have a strong inner need for connection, love, physical and emotional contact with others. We enhance our own well-being by building strong networks of relationships around us with all the other people in our lives. Positive relationships, such as strong ties with family and friends or weak ties with colleagues, lead to a sense of belonging (Sandstrom and Dunn, 2014).

Meaning and purpose Meaning involves the use of strengths not for one's self, but to fulfil goals which are perceived to be important. We are at our best when we dedicate time to something greater than ourselves. This could be volunteer work, belonging to a community or a civic or religious group, or learning for a specific goal. These activities have a sense of purpose, a compelling reason why individuals do what they do.

Accomplishment This signifies leading a productive, meaningful life. This pathway is pursued for its own sake, even when it brings no positive emotion, no meaning, and nothing in the way of positive relationships (Seligman 2011, p. 18). To achieve well-being, individuals must be able to look back on our lives with a sense of accomplishment: ,I did it, and I did it well'.

Using the PERMA framework as our conceptual basis, we aim to demonstrate that a multidimensional assessment of employees' 
well-being can provide more specific information to build up a picture of the essential aspects of workplace well-being.

\subsubsection{Well-being in the workplace}

Work represents an important context for studying the wellbeing of individuals, especially because it provides different sources that impact on mental health, optimal social functioning and performance, and because it demands a significant portion of an employees' time and effort. Studying employee well-being is a very popular topic of research interest and, as a result, researchers have revealed various and numerous dimensions of work-related well-being. While early studies primarily focused on problems faced by employees (e.g. stress, burnout, dissatisfaction), recently more and more of research has focused on the positive side of employee well-being and on strengths (Calabrese et al., 2010).

Why is employee well-being so important? Individuals' experiences at work, be they emotional or social in nature, obviously affect them. Well-being can potentially affect both workers and organizations in different ways. Workers with poor well-being may be less productive, make lower quality decisions, be more prone to be absent from work, and make consistently diminishing overall contributions to organizations (Price and Hooijberg, 1992).

Most studies on well-being examine separate constructs such as engagement, satisfaction, mental health or happiness. It is very clear that well-being at work is multidimensional (Grant et al., 2007; Page and Vella-Brodrick, 2009). Many concepts and measurements used in related research attempt to identify different elements of well-being, including job satisfaction, work engagement, organizational commitment, positive and negative emotions at work, positive and negative affect, intrinsic motivation, and thriving (Fisher, 2010).

Such separate aspects of well-being at work comprise an overall picture of well-being in the workplace.

In summary, it seems to be increasingly evident that employee well-being plays an important role at work. Wellbeing not only contributes to reducing the risk of mental problems, but also seems to facilitate many work-related issues, such as performance, quality of workplace relationships, motivation, engagement, etc. In this study we approach employee well-being from a positive psychology framework, adopting Seligman's (2011) multidimensional PERMA model.

\subsubsection{Measuring well-being}

Measures of well-being play an increasingly important role in applied research. Within psychology the expanding role of overall measures of well-being indicates a greater interest in the determinants of positive functioning. Measuring well-being can be done in a number of ways - there is no 'one size fits all' approach. In general, however, well-being measurement tends to be based on two principles: a) individuals, rather than groups, are the 'unit of measurement', even if we are ultimately interested in the well-being of a particular group of people. b) subjective, rather than objective, indicators provide the data. 'Subjective indicators' refers to questions which ask about feelings, experiences and judgements about life (NEF, 2012). Subjective measures of well-being capture people's feelings or real experience in a direct way, assessing well-being through ordinal measures (McGillivray and Clarke 2006; van Hoorn, 2007)

A number of questionnaires are available for gathering information on well-being. Most of these questionnaires focus on a single aspect of well-being (e.g. happiness, satisfaction, affect or mental aspect), while others aim to measure overall wellbeing (using multidimensional scales). The best known measurements on (subjective) well-being are summarized in Table 1.

Table 1 List of well-known well-being measurements

\begin{tabular}{ll}
\hline Well-being measures & Authors \\
\hline Oxford Happiness Inventory & Argyle and Hills, 2002. \\
Subjective Happiness Scale & Lyubomirsky and Lepper, 1999. \\
Approaches to Happiness Scale & Peterson, 2003. \\
Authentic Happiness Inventory & Peterson, 2005. \\
Satisfaction with Life Scale & $\begin{array}{l}\text { Diener, Emmons, Larsen and } \\
\text { PANAS (Positive and Negative }\end{array}$ \\
Affect Schedule) & Watson, Claek, Tellegen, 1988. \\
Affect Balance Scale (ABS) & Bradbum, 1969. \\
Psychological Well-Being Scales & Ryff, 1995. \\
Psychological Well-Being Scale & Diener and Biswas-Diener, 2009. \\
Warwick-Edinburgh Mental & Clarke et al., 2011. \\
Well-being Scale (SWEMWBS) & \\
Friedman Well-being Scale & Friedman, 1992. \\
\hline
\end{tabular}

Only a few scales cover factors associated directly to workrelated well-being. One such scale, the Workplace PERMAProfiler (M. L. Kern, 2014) is under development, and is - as it name indicates - based on Seligman's PERMA model as a theoretical framework. Several work-specific well-being questionnaires have been developed in the last years (e.g. Parker and Hyett, 2011; Orsila et al., 2011) and it is expected that an increasing number of work-specific questionnaires will be developed in the future. In this paper, we build upon Seligman's (2011) PERMA model as an organizing framework for measuring workplace well-being. We aimed to develop a comprehensive measure for assessing workplace well-being on the basis of positive psychology concerns and the PERMA model.

\section{Method}

\subsection{Participants and procedure}

A 56-item questionnaire was completed by a sample of 397 employees from different types of organizations. Data were gathered in paper and pencil form in groups during the 
postgraduate course lessons at BUTE. The participants were 153 males and 244 females. The participants' ages ranged from 26 to 57 years, with a mean of $41.38(\mathrm{SD}=7.81)$.

\subsection{Measures}

Items focusing on the five elements of PERMA model were constructed and gathered by a 6 member group of psychologists and MA psychology students. We gathered as many workrelated well-being items that covered Seligman's definitions of each domain of PERMA as possible. The next step was the construction of a 56-item questionnaire covering positive emotions, engagement, positive relationships, meaning and accomplishment relating to work settings.

The preliminary scale structure was evaluated by factor analysis with Varimax rotation in order to minimise correlations between components. Reliability was evaluated by Cronbach's alpha coefficients of internal consistency. The preliminary scale was shortened to 35 items by eliminating the items with the least favourable psychometric properties.

\section{Results}

The questionnaire data analysis was designed to identify the contents, elements and factors of psychological well-being based on the related literature. Theoretical approaches in the literature of well-being differ in the number and content of explanatory categories they propose. This study attempts to investigate which factor structure covers most of the construct in a Hungarian sample.

Factor analysis was applied, not only to reduce numbers of variables but to reveal underlying connections between variables. Additionally, based on the results it is possible to attempt to describe and explain the perception structures of participants. The characteristics that affect psychological well-being are very diverse so our primary goal when grouping items was to identify a meaningful but easy-to-use factor structure.

Firstly, explanatory factor analysis was applied to the total sample of 56 items. Factor analysis of the total sample resulted in 13 factors, and the number of item variables was 56. Sampling adequacy was measured with the Kaiser-Meyer-Olkin index, which resulted in 0.913 ( $\mathrm{p}=0.000)$, high above the commonly recommended value, and thus suitable for factor analysis. Initial eigen values showed 13 factors, which explained $63.5 \%$ of the variance of the total variables. It would appear, then, that thirteen factors cover the variables structure relatively consistently.

Based on the theoretical model and statistical results, our primary goal was to develop a more consistent factor structure. Hence, based on the results of the explanatory factor analysis, 8 items were eliminated because some failed to meet the minimum criteria of communality values $(0.3)$, while others had a primary factor loading above 0.5 .

Secondly, factor analysis was conducted on 46 items with 8 predetermined factors, since 5 factors were eliminated after the explanatory factor analysis because of insufficient value of primary factor loading. The result of the KMO index was 0.913 $(\mathrm{p}=0.000)$, high above the commonly recommended value and suitable for factor analysis. $58.08 \%$ of the variance of total variables was explained by 8 factors. A total of two items were eliminated because of communality of 0.3 or above: "I always know in advance what the next step I need to do will be" and "I just plan short-term, small goals, those are for sure".

Thirdly, factor analysis was conducted on 46 items with 6 predetermined factors, since 2 factors were eliminated at a previous step because of insufficient values of factor loading above 0.3 for all items. The KMO index result was 0.905 $(\mathrm{p}=0.000)$, high above the commonly recommended value and suitable for factor analysis. $58.27 \%$ of the variance of total variables was explained by 6 factors. 35 items were selected after all non-contributing items with factor loading above 0.5 were removed. Based on the factor loading values, a strong connection was found $(>0.5)$ between the majority of the items and underlying factors.

\section{First factor - Negative aspects of work}

The most important factor in the factor structure which indicated the largest reliability value contains 8 items, each with factor loadings between 0.557-0.781. This factor explains $26.1 \%$ of the variance. Effects causing work-related negative feelings were of the greatest importance, for example the influence of colleagues, or tasks exceeding one's capabilities or skills. "I feel I do not fit in with my colleagues", "Work demands exceed my abilities". Negative feelings related to the nature of the work seem less important, for instance "It is hard to be enthusiastic about my work".

\section{Second factor - Meaning of work}

The second most important factor in factor structure indicated second largest reliability. It contains 6 items, each with a factor loading between 0.587 and 0.739 . This factor explains $9.4 \%$ of the variance. Items connected with the meaning and usefulness of the work had higher factor loading: "My job has significance". Lower values were related to attitude and the method of individual work (engrossment, all-out effort) "I work with full effort".

\section{Third factor - positive relationships}

The third factor contains 5 items with factor loadings between 0.614 and 0.833 . This factor explains $7.6 \%$ of the variance. The most important item concerned trust in colleagues, "In most cases I can count on my colleagues", while the item: "There are many common themes with my colleagues" had the lowest value of factor loading.

\section{Fourth factor - engagement, flow}

The fourth factor contains 6 items, with factor loading between 0.554 and 0.797 . This factor explains $5.6 \%$ of the variance. The items with higher factor loading were related to happiness and inspiration caused by work situations " $M y$ job makes me happy" and "My job inspires me". An example of a 
less important one was: "At work, I more frequently have positive emotions than negative ones".

\section{Fifth factor-positive emotions, optimism}

The fifth factor contains 5 items, with factor loading between 0.526 and 0.675 . This factor explains $4.9 \%$ of the variance. The most important items were related to an optimistic mind-set and positive perceptions e.g. "I look to the future with optimism", while lower factor loadings were connected with positive emotions about the workplace e.g. "I feel positive at work".

\section{Sixth factor - achievement, success}

The sixth factor contains 5 items with factor loadings between 0.508 and 0.740 . This factor explains $4.6 \%$ of the variance. The strongest connection of this factor was with items about coping with obstacles "I will achieve what I want against all odds." The weakest correlation was with high performance in work: "My job performance is outstanding."

Reliability analysis of factors was examined using Cronbach's alfa. All of the factors seem reliable $(>0.7)$. These results indicate a high level of consistency between the items of each factor.

Table 2 Psychometric properties of the final questionnaire

\begin{tabular}{lllll}
\hline & Factor name & $\begin{array}{l}\text { Number } \\
\text { of items }\end{array}$ & $\begin{array}{l}\text { Cronbach's } \\
\text { Alfa }\end{array}$ & Variance\% \\
\hline 1. & Negative aspects of work & 8 & 0.86 & 26.1 \\
2. $\quad$ Meaning & 6 & 0.80 & 9.4 \\
3. $\quad$ Positive relationships & 5 & 0.83 & 7.6 \\
4. $\quad$ Engagement & 6 & 0.81 & 5.6 \\
5. $\quad$ Positive emotions & 5 & 0.79 & 4.9 \\
$\quad$ - Optimism & Accomplishment & 5 & 0.73 & 4.6 \\
\hline Total Variance & & & 58.27 \\
\hline
\end{tabular}

\section{Discussion}

\subsection{Implications}

This is the first study in Hungary to empirically apply the PERMA model to examine the well-being of individuals and its relationship to work. In evaluating the results we will attempt, in addition to the personal aspect, to outline the application of our results in organizational settings.

Our study has confirmed that the development of a new questionnaire based on the PERMA model can give a picture of overall well-being at work, and we explored evidence for six separate factors that provide specific value for work-related determinants of well-being. Our results confirmed that the theory of overall well-being can be described by a multidimensional approach which in practice gives more information about opportunities for change. On the other hand, using six factors provides us with an opportunity to form feedback to determine the points of intervention and development in organizational settings.
If levels of well-being are low interventions can be made in various ways that are most focused on increasing positive emotions and reducing negative emotions at work. Positive relationships between employees proved to be a very important factor in the prediction of job satisfaction and organizational loyalty. However, the level of overall mental health and well-being was increasingly influenced by negative factors at work and positive emotions, such as Engagement and the Meaning of work.

The differentiated patterns of the questionnaire achieved by using multidimensional scales enable the adoption of a more tailored approach to support well-being in the workplace. How can employees' well-being be supported and improved in an organization? One example is that during meetings there can be more discussion of the positive results employees have achieved and of what works well in the department. It may be important to increase the number and timing of discussions about results, and to reduce, but not eliminate the amount of time spent on discussing errors and failures. This practice can improve employees' level of well-being by setting clear goals relating to their personal development that are consistent with the PERMA principles. If the majority of teams in a given organization are open to using this practice, then the positive psychology approach may become a significant factor in the formation of the organizational culture.

\subsection{Application of the work-related well-being questionnaire}

\subsubsection{Feedback for employees}

The results of the well-being questionnaire may help to raise awareness at an individual level of the factors that determine whether employees feel good at work. Focusing on positive factors, they can reconsider their role, attitudes, and relation to work. They can search for opportunities to change in a constructive way in order to develop their social and working environment. Based on these:

- they can strengthen their personal resources to be better utilized,

- they can be happier and take pride in seeing their own role in the organisation,

- they can work to the best of their abilities as individuals, cooperating with their colleagues,

- it generally enhances his/her positive experience of the work.

\subsubsection{Feedback for leaders}

The individual results clearly indicate the level of wellbeing of each employee. The level of an employee's loyalty can highlight the degree of his/her commitment to the organization, the work, his colleagues, and the tasks. The summarized results of the questionnaire of a given department can inform decision makers and others about its retaining power and its work climate. Using the questionnaire at regular intervals can 
indicate increasing or decreasing levels of expected staff turnover, absenteeism, and internal conflicts.

\subsubsection{Organizational diagnosis and development}

Many companies strongly believe that their most important resources are their employees. In order to identify and activate the inherent strengths employees have, one of the most appropriate tools is making a PERMA-based diagnosis. To study well-being determinants can be the starting point for SOARbased organization development, and it can help to achieve the organization's vision (Cooperrider-Whitney-Stavros, 2008).

The repeated use of the work-related well-being questionnaire can serve as an evaluation tool: its results can provide information not only about the healthy functioning of an organization, but also about an increasing level of performance, or even tension, and can indicate the necessity of organizational transformation. While this questionnaire should, of course, be used with other diagnostic tools, positive psychological measurement and the positive psychology approach can give a strong positive reference points for improvement and development.

\subsubsection{Employee satisfaction}

To date, most employee satisfaction measurements focus on determinants of dissatisfaction. Research experiences have shown that in some cases, the answers given are not completely honest. Our well-being questionnaire focuses on positive factors, and respondents are not presented with critical factors, thus strengthening the satisfaction-based approach. Using the work-related well-being questionnaire presented in this study, reliable and quickly applicable results can be obtained in a short time based around the 6 factors that also provides a transparent picture of the level of job satisfaction.

\subsubsection{Eustress vs. distress}

Frequently focussing on negative events may intensify feelings of anxiety, apathy, anger or even the emotional state of despair and distress in leaders and employees. For evolutionary reasons, most people are not prone to muse on good and joyful things, but instead tend to analyse bad events in depth. This tendency often reduces a sense of comfort, increases the risk of burnout, and inhibits healthy mental function. By investigating and enhancing positive emotions and relationships, providing meaningful work, and supporting personal goals and fulfilment (all of which represent PERMA dimensions), we can increase the presence of eustress, resulting in better performance, selfefficacy, motivation, and commitment to work.

\subsubsection{Motivation at work}

People tend to think too much about what goes wrong and too little about what goes well with their work and activities. This may have a negative impact on motivation at work. Using personal results of work-related well-being questionnaire, and based on this information, we can set personal goals for the development of each employee, with a focus on positive events linked to productivity instead of obstacles. All of these considered, if greater emphasis is placed on the individual's strengths and efforts, he/she can be motivated to perform better. Regular back-testing encourages the success and the progress of care, and helps to maintain the motivation of individuals and teams.

\subsubsection{Energizing the organization}

Positive relationships, meaningful work, and improved awareness of positive emotional reinforcement can be beneficial for organizations. We have some experience of this. Working with a construction company, without staff turnover, and where $90 \%$ of employees work together day by day, we tried to develop the aforementioned three factors for more than ten years. It was exciting to see the effects of our work. The team of leaders and key colleagues were completely elated, and this heightened energy made their jobs extremely creative in this development process. They were able to discuss issues persisting for a long time in a positive atmosphere, and were able to think in a constructive way about the much-debated annual plan.

\subsubsection{Career Planning}

In the process of career planning and development individuals determine from where to where they wish to go. Getting ahead does not necessarily mean a higher position, but may also be perceived in terms of more professional and personal development, or new and more interesting tasks. This work-related well-being questionnaire may provide a useful measurement in career planning related to personal needs and motivations, or for those who plan to change their career. After changes in employment, this questionnaire can be applied to measure success and the extent of adaptation to the new job, or even where he/she is actually in the process of individual self-fulfilment.

\section{Summary}

A short and reliable work-related well-being questionnaire was the main result of the study. Based on the results, the workrelated well-being questionnaire was developed to provide a self-rating questionnaire reflecting Seligman's theoretical model of well-being. This questionnaire comprised from five to eight items for each of the five well-being domains, and we also explored a sixth one: the negative aspects of work. There was evidence of generally high internal consistency, composite reliability, and variance extracted for the global and the six domains of the work-related well-being. The exploratory factor analysis indicated strong support for its construct validity. These results are consistent with our conceptualization of work-related well-being as an extension of the PERMA model that is constructed around six different factors.

In conclusion, from our results we were able to determine that our 35-item questionnaire effectively estimates perspectives on 
work-related well-being. The applications of our results, as we have outlined above, may encourage organizations to evaluate work-related well-being at different workplaces. In addition, items should be researched in organizations with different aims, in different occupations, and with a larger population. Measuring changes over time, e.g., by use of annual yearly questionnaires may be more helpful in identifying the complex phenomenon of work-related well-being.

Employees' well-being or the lack of it can play a critical role in the life of organizations. It may influence rates of absenteeism, or fluctuation, workplace conflict and cooperation, as well as personal performance. All in all, it has a significant impact on organizational success. Hence it is strongly recommended that well-being at workplaces should be assessed from time to time. Improving well-being at work focuses on helping employees to:

- strengthen their personal resources

- flourish and take pride in their roles within the organisational system

- function to the best of their abilities, both as individuals and in collaboration with their colleagues

- have a positive overall experience of work

(National Economic Foundation, 2014)

Improved employee well-being contributes to individual motivation and health, as well as to corporate competitiveness (Grawitch et al., 2006). Employees with high well-being can be much more productive than those with low levels of well-being; they are likely to experience fewer motivational problems; they are more resilient to or welcoming of change and they are more likely to be engaged with the organization's goals. In order to attain these potential benefits, we need to measure the underlying factors that create well-being at work, and this 35-item work-related questionnaire can be a very useful tool to make the first step.

\section{References}

Calabrese, R., Hester, M., Friesen, S., Burkhalter, K. (2010). Using appreciative inquiry to create a sustainable rural school district and community. International Journal of Educational Management. 24(3), pp.250-265. https://doi.org/10.1108/09513541011031592

Cooperrider, D. L., Whitney, D., Stavros, J. M. (2008). Appreciative Inquiry Handbook : For Leaders of Change. Crown Custom Publishing, Inc.:Brunswick, OH. Berrett-Koehler Publishers, Inc., San Francisco.

Diener, E., Seligman, M. (2004). Beyond money: Toward an economy of well-being. Psychological Science in the Public Interest. 5(1), pp.1-31. https://doi.org/10.1111/j.0963-7214.2004.00501001.x

Diener, E., Suh, E., Lucas, R. E., Smith, H. L. (1999). Subjective well-being: Three decades of progress. Psychological Bulletin. 125(2), pp. 276-302. 1999. https://doi.org/10.1037/0033-2909.125.2.276

Diener, E. (2009). Subjective Well-Being. In The Science of Well-Being (Diener, E. (ed.)), pp. 11-58, Springer, New York. https://doi.org/10.1007/978-90-481-2350-6_2
Fisher, C. D. (2010). Happiness at work. International Journal of Management Review. 12(4), pp. 384-412.

https://doi.org/10.1111/j.1468-2370.2009.00270.x

Forgeard, M. J. C., Jayawickreme, E., Kern, M. L., Seligman, M. E. P. (2011). Doing the right thing: Measuring wellbeing for public policy. International Journal of Wellbeing. 1(1), pp. 79-106.

https://doi.org/10.5502/ijw.v1i1.15

Gable, S. H., Haidt, J. (2005). What (and why) is positive psychology? Review of General Psychology. 9(2), pp. 103-110.

https://doi.org/10.1037/1089-2680.9.2.103

Grant, A. M., Christianson, M. K., Price, R. H. (2007). Happiness, health, or relationship? Managerial practices and employee well-being tradeoffs. Academy of Management Perspective. 21(3), pp. 51-63.

https://doi.org/10.5465/AMP.2007.26421238

Grawitch, M. J., Gottschalk, M., Munz, D. C. (2006). The path to a healthy workplace: A critical review linking healthy workplace practices, employee well-being, and organizational improvements. Consulting Psychology Journal. 58(3), pp. 129-147.

Higgins, E. (2006). Value from hedonic experience and engagement. Psychological Review. 113(3), pp. 439-460.

https://doi.org/10.1037/0033-295X.113.3.439

Huppert, F. A., So, T. T. C. (2013). Flourishing across Europe: Application of a New Conceptual Framework for Defining Wellbeing. Social Indicators Research. 110(3), pp. 837-861.

https://doi.org/10.1007/s11205-011-9966-7

McGillivray, M., Clarke, M. (2006). Human well-being: Concepts and measures. In: Understanding Human Well-being. (McGillivray, M., Clarke, M. (ed.)), pp.3-16. UNU Press, Tokyo. 2006.

Michaelson, J., Abdallah, S., Steuer, N., Thompson, S., Marks, N., Aked, J., Cordon, C., Pottws, R. (2009). National accounts of well-being: Bringing real wealth onto the balance sheet. New Economics Foundation, London. 2009.

National Economic Foundation (2014).Well-being at work. A review of the literature. p. 52. [Online]. Available from: http://b.3cdn.net/nefoundatio n/71c1bb59a2ce151df7_8am6bqr2q.pdf [Accessed: 25th January 2016]

Orsila, R., Luukkaala, T., Manka, M. L., Nygard, C. H. (2011). A new approach to measuring work-related well-being. International Journal of Occupational Safety and Ergonomics. 17(4), pp. 341-359. https://doi.org/10.1080/10803548.2011.11076900

Page, K. M., Vella-Brodrick, D. A. (2009). The 'what', 'why' and 'how' of employee well-being: A new model. Social Indicators Research. 90(3), pp. 441-458.

Parker, G. B., Hyett, M.P. (2011). Measurement of Well-Being in the Workplace: The Development of the Work Well-Being Questionnaire. Journal of Nervous \& Mental Disease. 199(6), pp. 394-397. https://doi.org/10.1097/NMD.0b013e31821cd3b9

Price, R. H., Hooijberg, R. (1992). Organizational exit pressures and role stress: Impact on mental health. Journal of Organizational Behavior. 13(7), pp. 641-651. https://doi.org/10.1002/job.4030130702

Ryff, C. D., Keyes, C. L. M. (1995). The Structure of Psychological Wellbeing Revisited. Journal of Personality and Social Psychology. 69(4), pp. 719-727. https://doi.org/10.1037/0022-3514.69.4.719

Sandstrom, G. M., Dunn, E. W. (2014). Social interactions and well-being: The surprising power of weak ties. Personality and Social Psychology Bulletin. 40(7), pp. 910-922. https://doi.org/10.1177/0146167214529799

Schaufeli, W. B., Bakker, A. B., Salnova, M. (2006). The measurement of work engagement with a short questionnaire: A cross-national study. Educational and Psychological Measurement. 66(4), pp. 701-716. https://doi.org/10.1177/0013164405282471

Seligman, M. (1998). The Presidential Addresses. In: APA 1998 Annual Report. Retrieved 
Seligman, M. (2002). Authentic happiness. Free Press, New York.

Seligman, M. (2011). Flourish: A Visionary New Understanding of Happiness and Well-being. Free Press, New York. 2011.

Seligman, M. E. P., Csikszentmihalyi, M. (2000). Positive psychology: An introduction. American Psychologist. 55(1), pp. 5-14.

Seligman, M. E. P. (1998a). President's column: Building human strength: Psychology's forgotten mission. APA Monitor. 29(1), p. 1.

Stiglitz, J.E., Sen, A., Fitoussi, J.-P. (2009). Report by the Commission on the Measurement of Economic Performance and Social Progress. [Online]. Available from: http://www.stiglitz-sen-fitoussi.fr/documents/rapport anglais.pdf [Accessed: 13rd December 2015] van Hoorn, A. (2007). A Short Introduction to Subjective Well-Being: Its Measurement, Correlates and Policy Uses. Background paper prepared for OECD Conference on Measuring Progress of Societies. University of Rome "tor Vergata" Apr. 2-3, 2007. [Online]. Available from: http://www. oecd.org/site/worldforum06/38331839.pdf [Accessed: 10th January 2016] 